\title{
interpretações da estrutura ocupacional na américa latina: o debate marxista e a heterogeneidade estrutural ${ }^{\star}$ interpretations on the occupational structure in latin america: the marxist debate and the structural heterogeneity
}

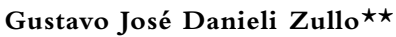 \\ Instituto de Economia, Universidade Estadual de Campinas, Campinas, São Paulo, Brasil
}

RESUMO

A partir de uma revisão bibliográfica, identificaremos as linhas de continuidade entre o debate marxista sobre a marginalidade social e a análise sobre o subemprego com base nos estudos da heterogeneidade estrutural. $\mathrm{Na}$ medida em que ambas as abordagens têm a história como ponto de partida, entendemos que as suas diferenças relativas à análise da estrutura socioeconômica latino-americana são, na verdade, complementares, o que evidenciaria a amplitude e a profundidade do conceito de subemprego para a realidade latino-americana, da qual destacaremos o Brasil.

Palavras-chave: Marginalidade social. Heterogeneidade estrutural. Subemprego.América Latina. História.

\begin{abstract}
From a bibliographical review, we will identify the lines of continuity between the Marxist debate on social marginality and the analysis on underemployment based on the studies of structural heterogeneity. Once both approaches have history as their starting point, we understand that their differences regarding on the analysis of the Latin American socioeconomic structure are in fact complementary, which would evidence the breadth and depth of under employment as a concept to Latin-American reality, of which we will highlights Brazil.
\end{abstract}

Keywords: Social marginality. Structural heterogeneity. Underemployment. Latin America. History.

* Agradeço a Alexandre Macchione Saes pelas críticas tecidas na defesa de minha dissertação de mestrado, as quais foram decisivas para a realização deste texto.

Submetido: 3 de fevereiro de 2016; aceito: 12 de dezembro de 2016.

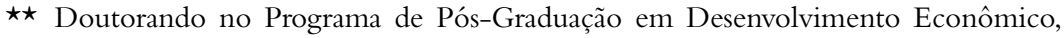
área de História Econômica, do Instituto de Economia da Universidade Estadual de Campinas. Mestre em Desenvolvimento Econômico, área de Economia Social e do Trabalho, pelo mesma instituição.E-mail: gustavozullo@gmail.com 


\section{Introdução}

Os processos de urbanização e industrialização nos países subdesenvolvidos foram acompanhados de problemas sociais particulares, diferentes daqueles que afligiam as economias centrais e hegemônicas. Inicialmente, essas idiossincrasias foram examinadas por autores como Nurkse e Lewis ${ }^{1}$, que procuraram compreender as relações fundamentais entre o tamanho do mercado, a acumulação de capital e a distribuição do excedente econômico. Todavia, a amplitude demasiadamente grande dessas análises diluía as especificidades regionais e nacionais. Foi apenas em um segundo momento, no âmbito da CEPAL, que surgiram as primeiras análises que valorizaram o processo histórico latino-americano. Ainda que Raúl Prebisch tenha lançado as bases do estruturalismo histórico ${ }^{2}$, foi Celso Furtado quem abordou com maior profundidade os aspectos sociais da economia. Foi o brasileiro que examinou mais de perto as estruturas econômicas e as estruturas de poder construídas no passado colonial e as associou à dualidade econômica e à distribuição de renda na América Latina ${ }^{3}$. Para ele, a modernização capitalista se desenrolou sem que fossem destruídas as estruturas arcaicas que haviam sido construídas durante a colonização. Pelo contrário, a expansão dos novos negócios dependeu da continuação da produção e do comércio internacional de produtos tropicais e de matérias-primas, o que concorreu para a formação do subdesenvolvimento contemporâneo, estrutura híbrida que acabou por se constituir em um processo histórico autônomo, e não necessariamente em uma etapa do desenvolvimento. Afinal, a renda gerada pelo empreendimento capitalista não era internalizada em uma proporção que desencadeasse a substituição do setor

1 Nurkse (1957) fez contribuições muito importantes à teoria do desenvolvimento. É dele, por exemplo, a formulação inicial de desemprego disfarçado, ou excedente estrutural de mão de obra, e a sua articulação ao tamanho do mercado interno e às possibilidades de acumulação de capital em situações subordinadas ao investimento privado, sobretudo se induzido pela demanda externa. Na mesma direção, Lewis (1969) indica as possibilidades da expansão do setor capitalista e o caráter do excedente econômico diante de uma economia marcada por um setor de subsistência que oferece uma quantidade ilimitada de mão de obra e de baixo custo. Além desses autores, ver Hobsbawm (1969).

2 Prebisch (2000).

3 Furtado (1961). Além disso, ver Prado Júnior (1987, 2011). 
de subsistência pelo setor moderno, o que gerou uma população à margem das atividades dinâmicas.

Os primeiros a buscarem uma explicação mais detida sobre os efeitos socioeconômicos da industrialização na América Latina foram intelectuais ligados à CEPAL, dentre os quais destacaremos dois sociólogos de viés marxista, que eram Anibal Quijano e José Nun ${ }^{4}$. Associando o estruturalismo histórico da Comissão às leituras de Marx, suas interpretações levaram ao limite a análise da dualidade. A partir de compreensões bastante peculiares sobre o exército industrial de reserva, esses autores discutiram a funcionalidade da estrutura marginal à reprodução ampliada de capital. Em outros termos, abordou-se as possibilidades de integração e absorção das estruturas econômicas e sociais do arcaísmo aos setores modernos, na medida em que estes avançavam e substituíam antigas formas de produzir. Todavia, essas posições não passaram incólumes. Autores marxistas ligados à CEPAL, ou influenciados por essa escola de pensamento, afirmaram que Quijano e Nun, a despeito das análises históricas sobre a formação do capitalismo monopolista na América Latina, haviam deturpado a realidade que se pretendia descrever. Dentre estes, destacaremos Francisco de Oliveira ${ }^{5}$, que destaca o caso brasileiro como caso sintomático das possibilidades e dos limites do processo de industrialização e urbanização nos países latino-americanos. Em $A$ crítica à razão dualista, o autor conferiu um espectro mais amplo à lei geral da acumulação, restituindo ao exército industrial de reserva uma única dinâmica, ainda que esta fosse desigual e combinada dentro de fronteiras nacionais. Todavia, a crítica de Oliveira se afastou da terminologia original, marginalidade social, ainda que fosse claro o seu diálogo com os autores acima mencionados. Coube a Lúcio Kowarick traduzir a análise de Oliveira, inteiramente calcada sobre termos marxistas, à linguagem do debate original sobre a marginalidade social na América Latina ${ }^{6}$.

No entanto, os autores de viés marxistas não foram os únicos a tratar de um tema tão polêmico. Economistas cepalinos, como Aníbal Pinto ${ }^{7}$, também abordaram o problema, recorrendo à heterogeneidade estrutural,

\footnotetext{
4 Quijano (1974, 1978), Nun (1969).

5 Oliveira (2003).

6 Kowarick (1977).

7 Pinto (1976).
} 
conceito fundamentado na verificação das diferentes produtividades do trabalho e que permite a identificação das descontinuidades de uma mesma economia. A partir dessa chave, Octavio Rodríguez aprofundou os estudos sobre o componente social da heterogeneidade estrutural e analisou o subemprego na economia brasileira, do que destacou a sua elevada relação com o perfil e o grau da histórica concentração fundiária ${ }^{8}$.

Em suma, cada um desses dois vieses será examinado com o intuito de destacar as suas linhas de continuidade, de modo a evidenciar a categoria subemprego como uma categoria que revela a particularidade e a amplitude da estrutura econômica e socioeconômica na América Latina, tomando o Brasil, por vezes, como caso paradigmático ${ }^{9}$. A primeira seção, portanto, é destinada à revisão bibliográfica dos autores marxistas, o que se justifica pelo fato de darem maior ênfase às determinações políticas e socioculturais sobre a estrutura econômica. $\mathrm{Na}$ medida em que se destaca a dominação de classe, as determinações sobre as estruturas econômicas e sociais ganham maior nitide $z^{10}$. Por fim, fecharemos a discussão com uma revisão dos textos que versam sobre a heterogeneidade estrutural e o subemprego, categorias que articulam o campo e os centros urbanos a partir dos movimentos da estrutura econômica propriamente dita, do que se extrai consequências sobre os aspectos socioeconômicos mais pertinentes a nossa análise.

\section{Uma discussão a respeito da marginalidade social na América Latina}

Nesta seção apresentaremos duas interpretações sobre a marginalidade social que não apenas divergem entre si, como, em boa medida, são

8 Rodríguez (1985). Para uma análise mais abrangente que aborda as relações entre estrutura agrária e outros aspectos econômicos e sociais, ver Furtado (1962, 1972, parte II).

9 Segundo Furtado (1983), as economias subdesenvolvidas e dependentes caracterizam-se por não terem como eixo de sua economia a acumulação de capital ao nível das forças produtivas.

10 Para uma interpretação que enfatiza os aspectos econômicos e sua intersecção com os aspectos sociais de uma situação de estabilidade, que cumpre exatamente a funções de coibir os aspectos construtivos da instabilidade sociocultural, econômica e política, ver Furtado (1972). Para uma análise sociológica, que foge ao escopo deste artigo, ver Fernandes (2008b, cap. 4). 
opostas, e cada uma dessas duas interpretações é composta por dois subitens. Nos dois primeiros subitens, que correspondem às interpretações de Anibal Quijano e José Nun, apresentaremos uma abordagem que compreende que a reprodução do capital monopolista seria quase que autônoma com relação às demais formas de organizar a produção na América Latina, o que implicaria uma determinada compreensão sobre a amplitude do exército industrial de reserva. Enquanto Quijano destaca os aspectos socioculturais e políticos da dinâmica econômica, Nun focaliza, através de uma interpretação sui generis do materialismo histórico, as particularidades socioeconômicas de um capitalismo subdesenvolvido e dependente. Já, nos dois últimos subitens, em que apresentaremos as análises de Francisco de Oliveira e Lúcio Kowarick, a reprodução da sociedade é apresentada através de uma perspectiva que articula simultaneamente todas as formas de organizar a produção, de modo que as formas arcaicas influenciam toda a dinâmica econômica e social, não estando restrita a suas próprias estruturas, portanto. De todo modo, tentamos apresentar os autores de modo a evidenciar a sua complementaridade. A análise de Nun, por exemplo, parece partir dos mesmos pressupostos usados por Quijano. Ao mesmo tempo, entendemos que a análise de Francisco de Oliveira, apesar de constituir um contraponto às interpretações dualistas, também compreende o subdesenvolvimento desde uma visão totalizante. Todavia, procura expor os nexos causais e os agentes fundamentais da estrutura e da dinâmica socioeconômica que o peruano diluíra em uma análise que se caracteriza por um alto grau de abstração. Por fim, entendemos que a análise de Kowarick oferece uma contribuição importante para situar o exército industrial de reserva dentro dos termos próprios do debate sobre a marginalidade social, visto que Oliveira usa apenas o conceito marxista de exército industrial de reserva.

\subsection{Anibal Quijano}

Para Quijano, desde a perspectiva do estruturalismo histórico, a marginalidade seria parte da problemática do subdesenvolvimento, o que faria dos grupos sociais o foco da análise, e não os indivíduos, como o fazia a sociologia estadunidense ${ }^{11}$. A marginalidade, portanto, deveria ser

11 Quijano (1978,p.14-18). Segundo o autor, os primeiros trabalhos que se debruçaram 
compreendida como uma "falta de integração em" (Quijano, 1978, p. 27), mas não uma falta de integração do indivíduo na sociedade, como decorrência de sua não adaptação a ela, mas como uma falta de integração que decorreria fundamentalmente das condições estruturais de integração da sociedade. Caberia ao estruturalismo histórico identificar os mecanismos que integram marginalmente um grupo considerável de pessoas a uma sociedade, o que requer o conhecimento das diferentes formas de organizar a produção e a estrutura hierárquica através da qual se relacionariam. Sob esse ponto de vista, entende-se que a sociedade e a economia seriam definidas, fundamentalmente, pela oposição entre um polo dominante, que controlaria o uso e a difusão das técnicas produtivas hegemônicas, e um polo marginal, que se valeria de técnicas rudimentares e se organizaria em bases não capitalistas. Além destes, haveria um polo intermediário, que, a despeito de não definir a natureza básica da sociedade, seria importante para lhe dar forma concreta, constituindo-se como um setor de produtividade e renda médias que se caracterizaria pelo uso de técnicas e tecnologias já ultrapassadas naquele momento. $\mathrm{O}$ estruturalismo histórico, entendendo a marginalidade como parte da formação histórica latino-americana, "parte do princípio de que o modo fundamental de integração dos diversos setores de elementos que conformam a sociedade é conflitivo e descontínuo, excluindo, pois, a ideia de um consenso universal entre os diversos setores de elementos na sociedade" (Quijano, 1978, p. 29-30, grifo nosso). Ou seja, seria a partir das circunstâncias históricas que seria definido o caráter dos conflitos em uma dada formação, assim como seriam definidos o caráter e a dimensão populacional dos polos em oposição.

A integração marginal de um elemento ou de um conjunto de elementos marginais na estrutura da sociedade indicaria a existência de um conflito radical que seria a expressão de uma tensão entre elementos opostos, que, todavia, não levariam necessariamente a uma ruptura com

sobre a marginalidade social, sobretudo nos EUA, abordaram o problema desde um ponto de vista estrutural-funcionalista, que, associado à ideia schumpeteriana do empresário inovador, focam a análise na personalidade marginal e entendem que a saída de tal situação seria encontrada pelo próprio indivíduo, na medida em que ele tenta eliminar e/ou romper barreiras. Ou seja, desde essa perspectiva, a marginalidade seria uma etapa que poderia ser subvertida a partir de uma adaptação do indivíduo ao meio. 
a estrutura dessa sociedade. Assim como Furtado, Quijano acreditava que o subdesenvolvimento se constituía historicamente como uma formação autônoma, não podendo ser confundida como uma etapa que antecede e condicionaria a passagem ao desenvolvimento. A expansão do capitalismo monopolista na América Latina, por exemplo, não beneficiou nem reduziu a participação dos setores secundário e marginal na economia e na sociedade. Ainda que o polo dominante fosse hegemônico, a maneira como ele mobilizava os demais níveis econômicos não alterou a condição de existência deles, sobretudo do polo marginal, "cuja existência não deriva das tendências que movem a estrutura básica da sociedade" $"$. Sem possuir os meios para reproduzir as condições materiais de existência dos indivíduos do polo dominante nem para acessar as modernas técnicas produtivas, não haveria a possibilidade de se superar a hierarquia social e econômica que singularizava, e ainda singulariza, as sociedades latino-americanas. O papel que a modernização industrial cumpriu foi o de elevar o grau em que se dava a exclusão dos elementos e dos grupos de elementos à margem das formas dominantes de organização, fazendo da marginalidade um modo ainda mais limitado de pertencimento e de participação ${ }^{13}$.A modernização não representava, nesses termos, uma oportunidade para se alterar a estrutura da sociedade global. Não se permitiria que os elementos intermediários e marginais fossem incorporados ao polo dominante. Por não partilharem dos mesmos padrões econômicos, sociais e culturais que norteariam a evolução histórica das estruturas básicas, os grupos hegemônicos impediriam que os elementos marginais as integrassem de forma ativa, o que caracterizaria o conflito daquelas formações como um conflito "radical"14.

Sem condições sociais, econômicas e culturais para impor um padrão autônomo de estruturação, a massa marginal resultaria como uma situação secular de dependência em relação às outras estruturas, conformando uma normalidade que se caracterizaria pela exclusão. Uma transformação que levasse à incorporação da generalidade da população às estruturas básicas da sociedade, às quais apenas o polo dominante tem acesso in-

\footnotetext{
12 Quijano (1978, p. 36).

13 Como indicaremos de forma implícita mais adiante, Kowarick (1977) faz críticas bastante pertinentes a essa interpretação.

14 Quijano (1974, p. 46-48).
} 
tegral, somente seria possível se alterado o próprio padrão de reprodução de suas estruturas desde o período anterior à industrialização, o que caracterizaria uma ação radical. Não seria possível fazê-lo através de uma simples incorporação daqueles que estão à margem dos padrões dominantes. Não se tratava de um problema de adaptação de elementos e de grupos de elementos inadaptados às estruturas básicas, o que caracterizaria um problema de adaptação na sociedade, que ajustaria os desajustados. O que Quijano evidencia é que o polo dominante não se interessaria em alterar o tipo de integração da sociedade, historicamente moldada para manter os diferentes elementos e diferentes grupos sociais nos seus respectivos lugares nas estruturas socioeconômica e política. A existência do polo dominante tal como se apresentava dependia da preservação das estruturas marginais, que se apresentavam como parte constitutiva da natureza básica das sociedades latino-americanas, que era a manutenção de pequenos núcleos de elementos plenamente integrados à custa de uma maioria precariamente integrada. As prerrogativas de que se valia dependiam da manutenção da estrutura global tal como se apresentava, o que levou o autor a afirmar que "esse sistema de dominação repousa sobre a base da marginalidade de uma parte da população da mesma sociedade" (Quijano, 1978, p. 50, grifo nosso).

Ainda que Quijano não aponte os nexos causais da marginalidade, limitando-se a explicitá-la como o resultado de um sistema de dominação que impediria a integração de setores da população que foram historicamente segregados, sua análise indica claramente que os agentes beneficiados pela industrialização não teriam interesses socioculturais, econômicos e políticos em alterar esse estado de coisas. Sendo a natureza das sociedades latino-americanas uma natureza excludente, que se renovaria historicamente sob formas determinadas, a marginalidade expressaria o agravamento de conflitos de toda ordem a partir da emergência do capital monopolista na América Latina. A marginalidade seria, nesses termos, a manifestação de uma situação de integração precária sob o comando do capital monopolista associado às estruturas internas de dominação, que atuariam diretamente sobre as possibilidade de integração global às estruturas que a beneficiavam. Assim, sob esse ponto de vista, o polo dominante estaria subordinado ao capital monopolista, do qual dependia para participar dos novos modelos de organização da produção. Ao mesmo tempo, o capital monopolista não interferia nas condições in- 
ternas de dominação dos países da região, que podiam, assim, exercer o seu poder e excluir os demais polos de existência. As novidades seriam, portanto, as novas contradições que emergiam dessa nova combinação entre dominação externa e dominação interna, sobre o que o autor salienta seus efeitos sobre as relações de produção ${ }^{15}$.

Durante o processo de industrialização na América Latina, que se desenrolou a partir de meados do século XX, os elementos em situação de marginalidade, que compõem proporções significativas da população de todos os países da região, não tiveram condições mínimas para ser absorvidos pelo setor monopolista, dada a exclusão a que estavam submetidos anteriormente. Os marginalizados se veriam ainda mais afastados das modernas condições de produção, o que reforçava o seu afastamento com relação às estruturas básicas que regulavam a vida em suas respectivas sociedades. De outro modo, a introdução de novos meios de produção e novas formas de acumulação capitalista tornou ainda mais instável e irregular o acesso do operariado ao sistema social e econômico dominante, dado que essas oportunidades ocupacionais ofereciam remunerações superiores às rendas que se pode auferir em atividades de produtividade mais baixa dos demais níveis de existência.Afunilar o peneiramento, digamos, restringiu as possibilidades de integração de uma quantidade enorme de pessoas, o que significou que os elementos em situação de marginalidade sequer viriam a constituir uma reserva aos trabalhadores ocupados nos setores economicamente mais avançados. A situação permanente de exclusão em que se encontravam lhes negava as possibilidades de adaptação desde uma perspectiva coletiva.Além disso, observou-se que toda e qualquer expansão do capital monopolista aprofundava e ampliava a situação de marginalidade, pois cada um desses movimentos destruía unidades de produção do polo marginal e competidores do polo intermediário que poderiam absorver elementos marginalizados. Em outros termos, a penetração abrupta do capital monopolista, resultado dos interesses dominantes que governam a evolução das sociedades latino-americanas, levou os níveis intermediários e marginais a uma integração ainda mais descontínua e conflitiva do que a anterior, quando a maioria estava ocupada em atividades rurais e na indústria predomina-

15 Em alguma medida, essa análise se assemelha à de Fernandes (2005). 
va uma tecnologia mais simples ${ }^{16}$. A expansão do capital monopolista foi incapaz de generalizar os efeitos da modernização para toda a matriz produtiva, que permanecia fundamental e extremamente heterogênea, porém sob uma nova configuração. A partir do predomínio do capital monopolista, os trabalhadores passaram a ocupar um nível ainda mais secundário, na medida em que a expansão do capital monopolista levou a uma redução do controle sobre os recursos necessários a sua produção, assim como também se perdia espaço no mercado.

Devido à superioridade de sua produtividade, o polo dominante possuía as condições para ditar o ritmo e a intensidade da expansão econômica, o que não se restringia a sua participação no mercado. $\mathrm{O}$ seu controle sobre os meios de produção também significava um controle sobre o tipo e a quantidade de força de trabalho necessária para dar andamento à nova articulação setorial. Mas não apenas a quantidade e a qualidade de sua mão de obra seriam afetadas, dada a grande influência do capital monopolista sobre as demais formas de organizar a produção. $\mathrm{Na}$ medida em que as novas técnicas de produção requeriam novas habilidades do trabalhador, a preparação que este recebia também era diferenciada, o que gerou novos conflitos e formas de excluir, pois nem toda a classe trabalhadora receberia o treinamento necessário. Para se ocupar um posto de trabalho no nível hegemônico, haveria que se possuir uma qualificação crescentemente exigente, que não estaria à disposição de todos no mercado de trabalho urbano ${ }^{17}$. Encontrar trabalhadores com a especialização requerida pelo nível hegemônico torna-se, portanto, uma tarefa difícil, mesmo porque muitas vezes não havia conexão social nem cultural com as zonas em que se inseriam abruptamente as empresas monopolistas. Em outros termos, a valorização do capital monopolista aprofundou a descontinuidade na reprodução da sociedade como um todo. Pelo contrário, as novas articulações geradas a partir do polo hegemônico deveriam criar uma solução que viabilizasse o seu objetivo, que era o de criar uma força de trabalho habilitada a movimentar a acumulação de capital no nível monopolista, sem alterar a hierarquia polar que singulariza historicamente as formações latino-americanas. A maneira que se encontrou para solucionar esse problema foi uma parceria,

\footnotetext{
16 Quijano (1974, p. 394, 406).

17 Quijano (1974, p. 408).
} 
digamos, entre Estado e capital monopolista, que criaram programas de treinamento e especialização que acabavam por criar um mercado de trabalho exclusivo a suas necessidades, o que impediria, ao mesmo tempo, que outros trabalhadores representassem algum tipo de pressão àqueles ocupados no polo dominante ${ }^{18}$. Ou seja, acabava-se por criar mecanismos institucionais que impediam que o polo marginal funcionasse como um legítimo exército industrial de reserva aos trabalhadores do polo dominante, levando-se em conta que os elementos e os grupos de elementos que ocupavam posições socieconômicas marginais geralmente estavam também inseridos em outras estruturas marginais, como seria o acesso e o tipo de transporte, de moradia, de educação etc. O máximo a que a força de trabalho que compõe esse polo poderia aspirar seria uma ocupação e uma integração no nível intermediário da sociedade, o que leva Quijano a afirmar que a força de trabalho do polo marginal se comportaria como um exército de reserva apenas ao setor competitivo, em que a qualificação exigida não seria tão elevada ${ }^{19}$. De tal modo, as populações que comporiam o exército industrial de reserva do polo dominante seriam os elementos desocupados desse mesmo polo e, a depender de circunstâncias pontuais, os elementos mais qualificados do polo intermediário.

Portanto, a análise implica uma segmentação do mercado de trabalho em duas instâncias tão rigidamente separadas, que a força de trabalho no nível marginal já não representaria uma reserva no nível hegemônico, tornando-se, por isso, supérflua à reprodução ampliada do capital ${ }^{20}$.

\subsection{José Nun}

Ainda que a conclusão a que chegou se assemelhe à de Anibal Quijano, José Nun trilhou um caminho diferente. Em vez de entender a marginalidade como um tipo de integração, Nun se esforça por situar o problema da marginalidade no nível das relações de produção. Sua interpretação do materialismo histórico, todavia, é bastante peculiar ${ }^{21}$.

\footnotetext{
18 Quijano (1974, p. 418-419).

19 Quijano (1974, p. 414). É importante frisar que o autor não avança na análise do êxodo rural, tratando-o como um simples dado.

20 Quijano (1974, p. 424-425).

21 Para uma crítica conceitual a Nun (1969), ver Cardoso (1971).
} 
Atento às idiossincrasias da realidade latino-americana, Nun entende que diferentes modos de produção coexistiriam em um mesmo espaço e em um mesmo tempo cronológico, sendo o capitalismo monopolista o modo de produção dominante em meados do século XX, o que lhe abriria a possibilidade de criar os seus próprios mercados, inclusive o mercado de trabalho, tal como o afirmara Quijano ${ }^{22}$.

Nun fundamenta-se em uma leitura conjunta de $O$ capital e dos Grundrisse, e neste último estaria indicado que todos os modos de produção teriam a sua própria superpopulação relativa, formada pelas parcelas da população que não conseguiriam vincular-se aos meios de sua própria reprodução nem aos meios de produção relativos a um dado nível de desenvolvimento. Tal interpretação lhe informaria que a emergência do capitalismo monopolista teria tornado o exército industrial de reserva insuficiente para explicar a "totalidade histórica singular" que se verifica na América Latina, dependente e subdesenvolvida ${ }^{23}$. Na medida em que o exército de reserva representaria apenas a população excedente de um dos modos de produção em vigor, que seria o capitalismo monopolista, a sua força explicativa seria enfraquecida. Por outro lado, a parcela da força de trabalho que somente teria condições de preencher um posto de trabalho nos setores concorrenciais, de tecnologia mais simples e que exigiriam menor qualificação, configuraria uma segunda superpopulação relativa.

Em seu sentido mais geral, cada superpopulação relativa seria formada pela população que excederia os limites representados pela "população adequada", que seria a porção de trabalhadores diretamente envolvida com os meios de produção de cada modo de produção. A combinação entre esses meios de produção, situados em um determinado estágio de desenvolvimento, e a população adequada estabeleceria, de uma só vez, os limites da população excedente, considerada virtual em relação a esse mesmo modo de produção porque afastada do processo produtivo, ainda que estivesse disposta e apta a fazê- $\mathrm{lo}^{24}$. Em todo e qualquer modo de produção, o processo de acumulação regularia, portanto, a demanda de trabalho, a população adequada e a população que excederia suas

\footnotetext{
22 Nun $(1969$, p. 210).

23 Nun $(1969$, p. 180).

24 Nun (1969, p. 181-182).
} 
necessidades de valorização ou de simples reposição do capital aplicado no início do processo produtivo. A forma específica que assumiria uma determinada superpopulação relativa dependeria, assim, da expansão ou da retração das atividades de seu respectivo modo de produção. Sendo assim, compreende-se que cada modo de produção determinaria a reprodução de sua própria força de trabalho, o que quer dizer que a reprodução da força de trabalho adequada à reprodução ampliada de capital no setor monopolista seria determinada pela concorrência intercapitalista nesse mesmo setor, que regularia a relação entre o exército ativo do setor monopolista e o exército industrial de reserva ${ }^{25}$. Assim, caso seja preservada uma mesma composição orgânica do capital durante o processo de acumulação, a expansão da atividade econômica levará o exército de reserva - em caso contrário, quando a concorrência intercapitalista se intensifica e a composição orgânica favorece o aumento do capital fixo, ou quando a atividade econômica é retraída a uma mesma taxa da composição orgânica, o exército ativo perceberá um decréscimo. De todo modo, nota-se que seria o próprio processo acumulativo que regularia tanto o exército de reserva como os salários.

Sob a hegemonia do capital monopolista, personificado em "empresas gigantescas" com acesso a mecanismos de financiamento que lhe permitem saltos de produtividade muito maiores do que o verificado anteriormente, o desenvolvimento tecnológico cumpriria o papel de eliminar do mercado parte expressiva do capital concorrencial, que antes absorvia uma quantidade maior de trabalhadores. Não obstante, a sofisticação das novas tecnologias requereria um conhecimento técnico maior por parte do trabalhador, o que inviabilizaria a possibilidade de que todo e qualquer trabalhador estivesse apto a ocupar um posto de trabalho nos setores e nos ramos tecnologicamente mais avançados. Ao mesmo tempo em que se expandiria a produtividade do trabalho, não só se reduziriam as possibilidades de uma simples substituição de trabalhadores, como também seriam criados empecilhos para a transferência da mão de obra ocupada nos setores menos desenvolvidos aos mais desenvolvidos. E não fosse isso bastante, o autor ainda indica que a quantidade de trabalhadores aptos a

25 Nun (1969,p. 189). Segundo Marx (2013,p. 690), a reprodução ampliada do capital, ou seja, a acumulação de capital, reproduziria as relações capitalistas de produção em escala ampliada, isto é, mais capitalistas, ou capitalistas maiores, de um lado, e mais assalariados, de outro. 
pôr em prática seus conhecimentos específicos sobre o manuseio da moderna maquinaria industrial tenderia a declinar, quando afastados por muito tempo dos setores monopolistas, sobretudo em países dependentes, onde a economia oscila com maior frequência e intensidade. Desocupados por lapsos de tempo muito dilatados, esses trabalhadores fatalmente perderiam suas capacidades técnicas específicas e, por isso, se encontrariam excluídos permanentemente do mercado de trabalho das empresas monopolísticas ${ }^{26}$. Em outros termos, José Nun afirma que, no capitalismo dependente, os trabalhadores excluídos do núcleo monopolista, desvinculados dos seus meios de produção específicos, perderiam sua funcionalidade para o processo de acumulação no setor monopolístico. Não poderiam ser entendidos, pois, como parte do "exército industrial de reserva", categoria específica desse setor. $\mathrm{Na}$ medida em que esses trabalhadores não representariam uma reserva aos trabalhadores demitidos do setor monopolista nem fariam qualquer tipo de pressão aos salários de seu exército ativo, eles não cumpririam as funções básicas de um exército de reserva, constituindo-se como uma superpopulação de outro modo de produção que não o capitalismo monopolista. De tal modo, compreende-se que o exército industrial de reserva seria composto pelos trabalhadores desocupados, aptos e dispostos a preencher uma vaga no setor monopolista, de um lado, e pelos trabalhadores ocupados nos setores do capital competitivo que estariam aptos e dispostos a ocupar um posto de trabalho nos setores do capital monopolista, de outro.

A superpopulação relativa dos setores concorrenciais ficaria, portanto, à margem dos setores e ramos monopolísticos, formando uma massa marginal afuncional/disfuncional em relação a esses mesmos setores e $\operatorname{ramos}^{27}$.

\subsection{Francisco de Oliveira}

Diferentemente dos dois autores apresentados acima, Oliveira (2003) não via qualquer empecilho para o uso do exército industrial de reserva como categoria explicativa para a totalidade da realidade brasileira.Além

26 Nun (1969, p. 199-200).

27 Nun (1969, p. 226).Ainda que a interpretação de Nun (1969) seja bastante polêmica, ela foi incorporada com algumas modificações por Souza (1999), cuja tese se alinha a Tavares e Serra (1971), Belluzzo (1978), Tavares (1981) e Possas (1982). 
disso, para o autor, o mais importante era salientar as estruturas internas de dominação como fundamento da dinâmica produtiva e ocupacional.

Em primeiro lugar, Francisco de Oliveira afirmou que eram várias as medidas necessárias para consolidar a transformação de uma economia de base agrária em uma economia eminentemente urbana. Naquele período, um enorme contingente populacional teria sido obrigado a migrar para os centros urbanos por causa do avanço das lavouras comerciais sobre as terras onde anteriormente predominava a subsistência. De modo a propiciar um horizonte médio para o cálculo empresarial, aquela massa de trabalhadores, que seguramente pressionaria para baixo os salários urbanos, não deveria ser recebida sem maiores atenções do Estado, que garantiria que a acumulação de capital ocorresse sem maiores entraves. Com o objetivo de orientar a reprodução ampliada do capital e tornar a empresa industrial a unidade mais rentável do conjunto da economia, o Estado, dentre outras ações, promulgou a Consolidação das Leis Trabalhistas, em 1943, e barateou o custo do capital através de subsídios fiscais e financeiros, os quais eram destinados tanto às manufaturas quanto à agricultura ${ }^{28}$. Ao mesmo tempo, o Estado abria estradas de rodagem pelo interior do país, o que não apenas viabilizava a expansão da fronteira agrícola, como também favorecia, enquanto fossem preservadas as formas arcaicas de produção rural, a ampliação do exército industrial de reserva. De tal modo, nota-se que o capital não apenas era favorecido, como também a classe trabalhadora era desfavorecida, e não apenas porque a agricultura de subsistência mantinha elevadas proporções da ocupação rural. O novo modelo de expansão capitalista, subdesenvolvido por definição ${ }^{29}$, atuava duplamente sobre as possibilidades de elevação salarial da força de trabalho ocupada nas cidades. De um lado, acirrava-se a competição por um posto de trabalho qualquer no mercado de trabalho urbano, o que pressiona negativamente o preço da mão de obra. De outro, a manutenção das estruturas produtivas arcaicas no campo manteve baixos os preços dos alimentos e das matérias-primas

28 Szmrecsányi (1998) indica que, nas décadas de 1960 e 1970, o Sistema Nacional de Crédito Rural (SNCR) concentrava sua atuação financeira em uma proporção semelhante à concentração fundiária, privilegiando algumas regiões e alguns produtos industrializáveis e exportáveis, como o café, a cana-de-açúcar, a soja e o trigo.

29

Oliveira (2003, p. 32-33). 
que compõem, respectivamente, parte importante dos custos de reprodução da força de trabalho nas cidades e do capital ${ }^{30}$.

É a partir dos interesses comuns das classes dominantes, notadamente a nova burguesia empresário-industrial e as velhas classes proprietárias rurais, que a expansão do capitalismo no Brasil deve ser entendida. Articulado a partir de dentro, o desenvolvimento capitalista das décadas de 1950 e 1960 representou a ampliação de uma economia capitalista que não seria a expansão de uma economia capitalista qualquer. Aquele foi o desenvolvimento de uma economia subdesenvolvida em que o "novo" se acomodava ao "velho", sendo notória a preservação de um dado padrão de relação entre trabalhadores e patrões que era herdeiro das relações sociais da escravidão ${ }^{31}$. Mais especificamente, a transição de uma economia agromercantil baseada no trabalho escravo para o trabalho livre não foi feita sem que suas marcas fossem sentidas no período seguinte, quando essa conflitiva unidade de opostos tomou novas formas sem alterar sua essência. Sob esse ponto de vista, o padrão de exploração do trabalho assalariado não diferiria substancialmente do padrão de exploração do trabalho escravo, o que foi ainda facilitado pelo fato de a transição ao trabalho assalariado ter se distendido no tempo. Na medida em que se diluía no tempo uma dada forma de exploração do trabalho, características do antigo padrão puderam ser prolongadas, o que conferiu ao trabalho assalariado no Brasil um elevado grau de exploração ${ }^{32}$.

Não obstante, a transferência do eixo de acumulação para a indústria e o processo de urbanização que lhe é subjacente trouxeram consigo a moderna tecnologia, que reforçava a pressão sobre o preço da força de trabalho. De tal modo, a crescente demanda de trabalho não era suficiente para absorver satisfatoriamente a oferta, formando um incipiente exército industrial de reserva que se formava antes mesmo de os salários

30 Oliveira (2003,p. 43-44). Argumento semelhante é o de Prado Júnior (1987,p. 173), que, todavia, não depositava tanta esperança na possiblidade de a industrialização dependente superar o passado colonial, como acreditavam Oliveira (2003) e Oliveira e Mazzucchelli (1977).

31 Essa herança também foi tocada por Furtado (2006). Todavia, quem mais avançou sobre essa questão foi Fernandes (2008a).

32 Ainda que Oliveira (2003, p. 62-66) não se aprofunde no assunto, outros autores, como Fernandes (2008b, cap. 1), analisaram a herança da escravidão de modo bastante fecundo, indicando que, em virtude de sua truncada transição ao trabalho assalariado, a proletarização no Brasil teria sido convertida em um privilégio. 
pressionarem os lucros. Valendo-se de uma tecnologia inadequada às necessidades sociais de um país subdesenvolvido como o Brasil, Oliveira afirma que o crescimento da indústria era incapaz de transpor para a geração de empregos a mesma importância que tinha na participação do PIB, ainda mais porque o setor terciário que se formava, "inchado" e "descapitalizado", reduzia os custos de se contratar serviços fora da unidade produtiva ${ }^{33}$. A existência desse mercado, "informal", barateava o custo variável das grandes empresas ${ }^{34}$.Apenas os trabalhadores ocupados nas tarefas consideradas essenciais à produção tinham suas relações de trabalho formalizadas de acordo com a legislação, visto que fazê-lo representava uma elevação considerável dos custos trabalhistas. Ou seja, a existência de uma rede de serviços urbanos de baixo custo formava um padrão de apropriação do trabalho alienado adequado àquela dominação de classe, sendo duas as razões fundamentais. A primeira delas é que a estrutura de custos das empresas seria reduzida porque a contratação trabalho informal reduziria a necessidade de se comprometer com custos trabalhistas relacionados à formalização da mão de obra. Em segundo lugar, haveria uma redução dos custos com salários, na medida em que os empregados dessas organizações se utilizariam dessa rede informal de trabalhadores na composição de seus gastos pessoais, o que indicaria que seriam os salários mais baixos da hierarquia ocupacional que determinariam a estrutura salarial. E não apenas porque o mercado de trabalho informal influencia decisivamente o poder de compra dos salários médios e elevados. A remuneração dos trabalho informais tende também a determinar o preço da força de trabalho dos postos mais baixos do setor capitalista. Como afirmara Oliveira, "longe de serem excrescência e apenas depósito do 'exército industrial de reserva', os serviços urbanos e de consumo pessoal são adequados para o processo da acumulação global e da expansão capitalista e, por seu lado, reforçam a tendência à concentração de renda" (Oliveira, 2003, p. 58, grifo nosso) ${ }^{35}$.

\footnotetext{
33 Oliveira (2003, p. 63-67).

34 Oliveira $(2003$, p. 76-77, 82).

35 Essa conclusão é diametralmente oposta à interpretação de Quijano $(1974,1978)$ e Nun (1969). Para Oliveira (2003), não haveria qualquer fração da classe trabalhadora que não fosse funcional.
} 
O nível dos salários de base dos empregados formais, determinante para toda a estrutura que está acima deles, sofreria uma dupla influência. De um lado, haveria um elemento estrutural que é o peso da dinâmica da economia informal, formada basicamente pelos trabalhadores que comporiam o exército industrial de reserva, sobre as demais formas de organizar a produção. Em segundo lugar, o Estado cumpriria papel importante na institucionalização do padrão deprimido de remuneração das empresas, porque o nível do salário mínimo seria muito baixo, o que levou Oliveira a afirmar que "a legislação trabalhista igualava reduzindo - antes que incrementando - o preço da força de trabalho" (Oliveira, 2003, p. 38). A baixa remuneração que se oferecia em alguns serviços que exigiam especialização levava alguns desses trabalhadores qualificados a buscarem ocupações que não exigiam qualificação, o que "impedia - ao contrário do que muitos pensam - a formação precoce de um mercado dual de força de trabalho" (Oliveira, 2003, p. 38). Ou seja, uma oferta relativamente baixa de ocupações que exigiam uma qualificação mínima por parte da força de trabalho, o que rebaixava os salários como um todo, revelou a existência de uma elevada taxa de exploração naquela economia.

De certo modo, o que está sendo reconsiderado é a natureza do subdesenvolvimento, entendido tal como o definiu Furtado (1961). Trazido para dentro da formação histórica nacional, sob uma perspectiva de longa duração e conjugada à dependência externa, procurava-se dissipar a dualidade que marcava o pensamento cepalino, o que fica nítido no trecho a seguir:

esse tipo de dualidade é encontrável não apenas em quase todos os sistemas, como em quase todos os períodos. [...] a oposição na maioria dos casos é tão somente formal: de fato o processo real mostra uma simbiose e uma organicidade, uma unidade de contrários, em que o chamado "moderno" cresce e se alimenta da existência do "atrasado", se se quer manter a terminologia. (Oliveira, 2003, p. 32)

Em suma, Oliveira (2003) põe em primeiro plano as estruturas internas de dominação como prolongamento da formação histórica do país, que, na contemporaneidade, preservaria e aprofundaria o subdesenvolvimento e a dependência externa. É a partir das relações sociais nativas que seria erguida a estrutura socioeconômica contemporânea, 
na qual o autor evidencia existir uma única população trabalhadora "excedente", que seria o exército industrial de reserva ${ }^{36}$.

\subsection{Lúcio Kowarick}

Porém, é Lúcio Kowarick quem, fortemente influenciado por Francisco de Oliveira, supera as análises dualistas dentro dos próprios termos do debate inicial.

Sua interpretação situou explicitamente a marginalidade social dentro de uma análise das relações sociais de produção típicas de formações dependentes e subdesenvolvidas, enfatizando conceitos como "contradição", "conflito" e "dominação" 37 . O autor afirma que a teoria da marginalidade deveria ser equacionada ao nível das relações de produção, sendo "um modo de inserção nas estruturas de produção" (Kowarick, 1977 , p. 19). Dessa maneira, os grupos marginais seriam aqueles cuja situação decorreria das contradições mais básicas e essenciais, as quais derivariam das idiossincrasias da acumulação capitalista em economias dependentes e monopolistas. $O$ problema central consistiria, então, em verificar como a força de trabalho seria integrada ao processo produtivo, na medida em que o capitalismo se expande, penetra e domina os diversos setores da economia, inclusive no campo.

A intensificação do processo de industrialização em uma economia dependente e subdesenvolvida liberaria das atividades arcaicas tradicionais, mais ligadas à produção, uma grande quantidade de trabalhadores que, tanto nas áreas rurais quanto nas áreas urbanas, passariam a ocupar postos de trabalho em atividades novas, porém, arcaicas, no setor terciário. Aumentariam exponencialmente as ocupações no comércio, os pequenos serviços de reparação e manutenção e os empregos domésticos remunerados, além de um sem-número de formas de desemprego disfarçado e várias outras formas de trabalho ocasional e intermitente que comporiam o cenário urbano das cidades latino-americanas. Todavia, a re-

36 Aqui, a palavra “excedente" segue a interpretação de Marx (2013, p. 705), que indica que o caráter excedente do exército industrial de reserva seria relativo apenas à massa de trabalhadores necessária para movimentar a massa de meios de produção no processo produtivo, o que não significa, sob hipótese alguma, que essa população não exerceria pressão sobre a remuneração do exército ativo.

Kowarick (1977, p. 13-18). 
novação dessas relações de produção não levaria a um desaparecimento das formas mais antigas de arcaísmo, o que de maneira alguma poderia caracterizar duas estruturas nem dois mercados de trabalho. O que ocorreria, na verdade, seria uma superposição, em que o antigo alimentaria o moderno. Nesse caso, as formas de produção econômica constituir-se-iam como partes integrantes de um único processo de acumulação, lembrando que as estruturas que concorreriam para o processo de industrialização liderado pelos setores e ramos hegemônicos e monopolistas não estariam dissociadas nem deixariam de ser favorecidas pela existência de formas pouco desenvolvidas de organizar a produção. Tais formas, marginais, encontradas em todos os setores, se reproduziriam igualmente no mercado, compondo uma única lógica estrutural, de tipo capitalista, que incorporaria as formas não tipicamente capitalistas de organizar a produção não como peso morto, mas como parte integrante do processo de acumulação ${ }^{38}$. Nesse sentido, é possível dizer que o processo de acumulação capitalista, sob a liderança da indústria, recorreria a diferentes tipos de relação de produção que corresponderiam a diferentes tipos de inserção no sistema produtivo, que se poderiam dividir simplificadamente em não marginais e marginais. As formas de organizar a produção que visam à obtenção de mais-valor e que ofereceriam condições mais estruturadas de trabalho e remuneração combinam-se às formas não tipicamente capitalistas de organizar a produção, o que caracteriza o padrão de acumulação capitalista na América Latina e aproximaria as funções dos marginalizados às de um típico exército industrial de reserva.

Estes tipos de trabalho não são apenas constantemente fecundados pelo sistema capitalista como também estão a ele estruturalmente articulados. É com estes cuidados que se pode usar o conceito de marginalidade para definir tais trabalhadores, ainda mais quando se tem em conta que $[. .$.$] guardam$ uma estreita aderência ao ciclo expansivo do capital, aparecendo no cenário econômico enquanto uma categoria classicamente definida como "exército industrial de reserva". (Kowarick, 1977, p. 83-84, grifo nosso)

Não haveria razão, portanto, para enxergar a dualidade tal como o fizeram Quijano $(1974,1978)$ e Nun (1969), uma vez que os trabalha-

38 Kowarick (1977, p. 60-61). Aqui, o autor se contrapõe à análise de Quijano (1978, p. 27), como indicamos anteriormente. 
dores marginalizados preencheriam aquelas duas funções básicas de um exército industrial de reserva, que seriam, grosso modo, o de constituir uma reserva ao exército ativo e o de pressionar para baixo os salários destes. Ademais, segundo Kowarick (1977), a mão de obra especializada não seria tão rara nem de tão difícil substituição, dado que sua formação não seria complicada nem demorada, e muitas tarefas seriam de fácil execução, o que inviabilizaria uma distinção rígida das estruturas produtiva e ocupacional ${ }^{39}$.

\section{Heterogeneidade estrutural, emprego e subemprego}

Passada a exposição do debate sobre a marginalidade social, seguiremos com a apresentação do conceito de heterogeneidade estrutural, fundamento sobre o qual se ergue o subemprego como categoria de análise para a compreensão da estrutura ocupacional latino-americana em sua especificidade e amplitude histórica. Mas não apenas isso. Na medida em que o conceito de marginalidade social é utilizado por Aníbal Pinto, fez-se necessária uma prévia apresentação do debate sobre a marginalidade social, para que o leitor não caísse em armadilhas que o termo suscita, uma vez que sua utilização já se tornou corriqueira e desprovida do devido rigor. Ou seja, entendemos ter sido necessário situar com maior clareza o conceito de marginalidade social, para evitar que a exposição da análise de Aníbal Pinto posicionasse o leitor desavisado em uma dualidade que entendemos não ser a chave de leitura mais adequada para a interpretação da estrutura socioeconômica na América Latina. O intuito maior seria evidenciar as linhas de continuidade entre as análises marxistas e as análises cepalinas, e não apenas de um ponto de vista teórico. Nas linhas que seguem, procuramos destacar aspectos econômicos que ainda não foram destacados, complementando a narrativa histórica que compõe parte essencial da exposição daquilo que se entende por subemprego.

Em primeiro lugar, examinaremos a contribuição de Aníbal Pinto sobre a heterogeneidade estrutural como um preparativo à leitura de Octavio Rodríguez. De um lado, Aníbal Pinto (1976) apresenta um

39 Kowarick (1977, p. 111-112, 153). 
breve panorama do processo de industrialização brasileiro, que a partir da década de 1950 aprofundou o desnível entre o setor moderno e o arcaico. De outro, Octavio Rodríguez (1985) observa as causas do êxodo rural e seus impactos sobre as ocupações agrícolas e não agrícolas. Evidencia, assim, o subemprego como um categoria própria de estruturas subdesenvolvidas, em que a concentração fundiária, reminiscência de um passado colonial, determina a evolução de um país.

\subsection{Aníbal Pinto}

Dentre as economias latino-americanas, a brasileira foi a que mais se afastou do modelo dual, em que o complexo exportador apresentava uma produtividade muitas vezes superior à do restante da estrutura produtiva. Segundo Aníbal Pinto, o grau de independência conquistado pelo Estado nacional teria sido suficiente para fazer com que a industrialização das décadas de 1950 e 1960 levasse ao surgimento e fortalecimento de um setor não exportador modernizado e capitalista, de elevada produtividade do trabalho, superior à média de alguns ramos do complexo exportador. Mais ainda, afirma que, na medida em que foram internalizados bens intermediários e bens de capital, a economia brasileira teria sido a economia latino-americana que mais reduziu a sua heterogeneidade estrutural no decorrer de seu processo de industrialização. Todavia, esse processo não foi suficiente para alavancar uma homogeneização tal como ocorrera no centro capitalista, em que o desenvolvimento industrial se consolidou e foi acompanhado da homogeneização da estrutura ocupacional. Aqui, ainda que o processo substitutivo tenha reduzido a participação de trabalhadores ocupados em atividades de baixa produtividade, a estrutura ocupacional não apresentou maiores alterações, e grande parte da força de trabalho permaneceu na marginalidade ${ }^{40}$.

Quando o desenvolvimento capitalista no Brasil foi acelerado em 1956, a indústria brasileira avançou qualitativamente, na medida em que internalizou setores produtores de bens de capital e de bens de consumo

40 Pinto (1976, p. 53), que identifica a marginalidade às ocupações de baixa produtividade, afirma que a marginalidade parece ter as funções e possibilidades de um exército industrial de reserva, o que aproximaria a sua interpretação às de Oliveira (2003) e Kowarick (1977). 
durável, que eram setores de produtividade mais elevada que a média da indústria nacional. Contudo, era exatamente essa maior eficiência que limitava o tamanho do mercado consumidor dos setores que vinham sendo instalados nos anos recentes. Os bens de consumo durável somente estavam à disposição das rendas elevadas, e a maioria da população, a despeito da expansão econômica, não possuía recursos financeiros para adquirir as novas mercadorias. Não obstante o diferencial de renda que caracterizava a estrutura salarial do país, os estratos sociais privilegiados tinham a sua disposição mecanismos de crédito desenhados precisamente para inflar o seu consumo de bens duráveis, como o automóvel, a geladeira etc. Ou seja, partia do Estado uma coordenação que garantia os tradicionais desequilíbrios da distribuição de renda, o que em nada se contrapunha aos interesses da classe empresarial, associados aos interesses externos e desinteressados de conquistar autonomia nacional ${ }^{41}$.

Fruto de uma industrialização dependente, sobretudo a partir da segunda metade da década de 1950, quando foi permitido ao capital internacional liderar o processo, a autonomia da economia nacional foi duramente solapada. A partir desse momento, esse capital introduziu obrigações financeiras que reduziam a intensidade e o alcance da industrialização brasileira, como foi no caso de pagamento de serviços derivados do uso de tecnologia de propriedade estrangeira. Não apenas se limitava a capacidade de reinvestimento, como também se colocou rápida e progressivamente a economia nacional em uma situação de endividamento externo. Ainda que houvessem outras possibilidades para dinamizar a indústria, como o seria a diversificação das exportações, o autor afirma que a orientação dada à industrialização brasileira não privilegiou necessidades sociais nem outros objetivos próprios de uma estratégia desenvolvimentista. As relações criadas pela nova situação entre o país e o exterior, que redundava em fortes pressões sobre o Balanço de Pagamentos, contribuíam para uma crescente alienação dos centros de decisão.Além disso, a baixa produtividade da indústria, ao menos quando comparada internacionalmente, revelava a sua inadequação em se constituir em plataforma de exportações que operasse no sentido de obter as divisas que financiariam as importações necessárias à continuidade do processo substitutivo. O desenvolvimento industrial autônomo, por-

41 Pinto (1976, p. 69-75). Essa mesma posição é defendida por Furtado (1972). 
tanto, não era possível naqueles termos, inclusive porque o setor primário-exportador resistia em perder a posição de principal fonte de divisas ${ }^{42}$.

Do ponto de vista social, uma das consequências mais significativas daquela industrialização que introduzia no campo os insumos e as máquinas agrícolas vinculadas à indústria moderna, de alta produtividade, foi o fluxo migratório da população rural. Mas não apenas de trabalhadores vindos do campo era composto o fluxo migratório que robustecia o mercado de trabalho das grandes cidades, sobretudo as do Sudeste, onde já se concentrava a produção industrial no Brasil e também o operariado ${ }^{43}$. Atraídos pelas oportunidades de trabalho que derivavam de uma expansão industrial que não eliminava a grande heterogeneidade estrutural, muitos saíam de cidades menores, para consolidar a formação do proletariado urbano. À míngua de investimentos, as cidades pequenas e médias de todo o país foram transformadas nos maiores dispersores de mão de obra ${ }^{44}$, o que proporcionou um aumento da oferta de trabalho acima da demanda nos centros industriais, a despeito do crescimento da atividade econômica. Ou seja, os processos de urbanização e industrialização alteraram profundamente a composição da estrutura ocupacional do país. $\mathrm{Na}$ medida em que a indústria foi alçada a setor dinâmico da economia, a estrutura ocupacional sofreu grande transformação, havendo uma queda relativa do setor primário em prol dos demais setores, eminentemente urbanos.

Em suma, poderíamos afirmar que a conservação da heterogeneidade estrutural evidenciou o poder das forças arcaicas no Brasil, aliadas menores do capital estrangeiro, no intuito de controlar o alcance e o sentido da modernização da economia ${ }^{45}$.

42 As posições de Pinto (1976) contrastavam claramente com as de Tavares, que afirmava que, "quanto mais desenvolvida está a estrutura industrial, mais internacionalizados e solidários são os comportamentos das grandes empresas transnacionais, nacionais e estatais" (Tavares, 1981, p. 41, grifo nosso).

43 Pinto (1976, p. 71-76).

44 Pinto (1976, p. 53). Como veremos, a posição relativa à origem da maioria dos migrantes difere da posição de Rodríguez (1985).

45 Afirmação semelhante é tecida por Prado Júnior, quando afirma, ainda que de modo mais veemente, digamos, que "não somente os interesses fundados na ordem passada, e ainda essencialmente dominantes, mas a inércia de toda a parte mais importante e substancial da estrutura e organização econômica do país que se constituiu em função de uma finalidade e é agora solicitada por outra. Uma análise atenta da 


\subsection{Octavio Rodríguez}

Seguindo a análise Aníbal Pinto, Octavio Rodríguez aprofunda a interpretação sobre a heterogeneidade estrutural desde a perspectiva da ocupação, formada por duas categorias analíticas, emprego e subemprego, definidas e diferenciadas uma da outra a partir de um critério básico, que é a produtividade do trabalho. Enquanto o emprego seria o trabalho realizado em atividades de alta produtividade, o subemprego se caracterizaria pela baixa produtividade dos meios de produção, o que evidencia a semelhança desse conceito com o de marginalidade social tal como definido por Pinto (1976), que o associa ao exército industrial de reserva $^{46}$. Nesse caso, o subemprego equivaleria à superpopulação latente e à superpopulação estagnada ${ }^{47}$, correspondendo a formas de ocupação mais afastadas da reprodução ampliada de capital, sendo também caracterizado por sua elevada participação na estrutura ocupacional por longos períodos de tempo. Tal definição, por sua vez, é decisiva para a análise daquilo que o autor entende por heterogeneidade estrutural, concebida como o estado em que as atividades de produtividade muito reduzida se prolongam no tempo como atividades que absorvem uma

organização econômica do país nos mostra que o essencial nela, desde a distribuição da população, a estrutura agrária, a disposição dos centros urbanos, a rede de transportes, até o aparelhamento comercial e financeiro, se dispõe sobretudo para atender aos objetivos que desde remotos tempos de sua formação até nossos dias, a ela essencialmente se impôs: a produção de gêneros exportáveis. E isso sem contar poderosos fatores sociais e políticos que agem no mesmo sentido. Não podia ser de outra forma depois de quatro séculos e tanto de hegemonia de tal sistema econômico, que somente em época recente entrou em sua fase de degradação" (Prado Júnior, 2012, p. 298).

46 Rodríguez (1985, p. 65).

47 Para Marx, a superpopulação estagnada "forma uma parte do exército ativo de trabalhadores, mas com ocupação totalmente irregular. Desse modo, ela proporciona ao capital um depósito inesgotável de força de trabalho disponível. Sua condição de vida cai abaixo do nível médio normal da classe trabalhadora, e é precisamente isso que a torna uma base ampla para certos ramos de exploração do capital" (Marx, 2013,p. 718). Por sua vez, a superpopulação latente irremediavelmente surge quando a produção capitalista se apodera da agricultura e retira da população rural as possibilidades de encontrar uma ocupação agrícola que, por isso, se encontrará "em vias de se transferir para o proletariado urbano ou manufatureiro, e à espreita de circunstâncias favoráveis a essa metamorfose" (Marx, 2013, p. 717) "sempre com um pé no lodaçal do pauperismo" (Marx, 2013, p. 718). 
porção considerável da força de trabalho. Assim, o subemprego seria o resultado de uma economia que se modernizaria apenas parcialmente, constituindo-se como uma expressão do atraso em que viveriam milhões de pessoas zonas urbanas e rurais.

Se, no início da década de 1950, a zona rural abrigava a maior parte dos subempregados, a precária situação do campo e as notícias que vinham das cidades iniciariam, em poucas décadas, um processo maciço de migração aos centros urbanos. Tendo contribuído de forma decisiva para configurar uma demografia crescentemente urbanizada, a questão agrária $e^{48}$, portanto, fundamental para entendermos a dinâmica e o perfil do mercado de trabalho urbano entre 1950 e 1980. De modo conjugado, a preservação da concentração fundiária, a expansão da produção agrícola de tipo capitalista e a expansão industrial provocaram enormes alterações na estrutura da ocupação. Na medida em que a modernização industrial permitiu a tecnificação da produção agrícola, aliada à expansão da fronteira destinada à grande exploração mercantil, milhões de trabalhadores rurais foram repelidos do campo e absorvidos nas cidades, onde se juntaram a uma massa já existente de subempregados urbanos ${ }^{49}$. A tecnificação da agricultura e a expansão de grandes propriedades monocultoras contribuíram decisivamente para desagregar a já frágil agricultura atrasada que era praticada nas grandes propriedades rurais, e muitos dos antigos parceiros foram impelidos à proletarização nas cidade. No estado de São Paulo, por exemplo, a valorização das terras próximas a rodovias e/ou a centros urbanos levou, com o apoio do Estado, à expansão do plantio de culturas comerciais em áreas que antes eram ocupadas para a subsistência, expulsando muitos colonos que trabalhavam naquelas terras. Todavia, muitos daqueles que passaram a residir nas cidades continuaram a ocupar, regular ou descontinuamente, uma atividade agrícola, ocasionando o surgimento de trabalhadores volantes, os chamados boias-frias. Ou seja, a modernização da agricultura, antes de pôr

\footnotetext{
48 Em linhas gerais, Rodríguez (1985, p. 73) indica que, fundamentalmente, a questão agrária corresponderia à expansão da moderna agricultura, que limita as terras a serem cultivadas para sustento próprio, e às condições prévias de concentração da estrutura fundiária, que permitem a preservação desse estado de coisas.

Rodríguez (1985, p. 63-73).
} 
um fim ao subemprego rural, apenas garantiu a sua reposição na cidade, onde não necessariamente ocupavam uma atividade não agrícola ${ }^{50}$.

$\mathrm{O}$ êxodo de trabalhadores rurais que não conseguiram superar a condição de subempregados nas cidades intensificou a concentração pessoal da renda, o que obedeceu a dois mecanismos básicos. O primeiro deles consistiria na enorme pressão que decorre do volume crescente de subempregados, que jogou para baixo a sua própria remuneração média, que cresceu mais lentamente que o salário dos empregados. Já o segundo estaria mais relacionado aos diferentes poderes de barganha dos sindicatos, o que, por sua vez, derivaria da capacidade de acumular que tem a indústria a que um dado sindicato está vinculado. Quanto mais moderno for o setor, maiores as chances de o sindicato aumentar o seu poder de negociação, afastando o salário de seus empregados do salário de base a que os empregados das indústrias tradicionais muitas vezes partilham $^{51}$. Por sua vez, a dispersão salarial dos empregados decorreria, em grande medida, do constante incremento da oferta de trabalho, o que quer dizer que a dispersão salarial depende do ritmo e da intensidade da absorção de subempregados às atividades de produtividade um pouco maior. Ou seja, ainda que o dinamismo da economia tenha sido suficiente para ocupar muitos dos trabalhadores que chegaram aos centros urbanos, fica claro que o crescimento do salário real médio estava subordinado ao salário de base por causa da elevada proporção de ocupados que recebem essa remuneração ${ }^{52}$. Já a concentração funcional da renda

50 Rodríguez (1985, p. 73). Diferentemente de Pinto (1976), Rodríguez (1985) ressalta o êxodo rural como principal motivo da formação de um volumoso mercado de trabalho com grande presença de subempregados.

51 O salário de base seria a remuneração dos empregos de menor produtividade das indústrias menores.

52 Rodríguez (1985, p. 74). Para uma análise que verifica estatisticamente a evolução do subemprego no período 1950-2000, ver Portugal Jr. (2012, p. 280), que aponta que a participação do subemprego se manteve estável nos anos de 1980, 1991 e 2000 , atingindo, respectivamente, os patamares de $28 \%, 36 \%$ e $29 \%$ dos ocupados. Ademais, identificamos uma afinidade substantiva entre as análises de Rodríguez (1985) e Prado Júnior, que coloca a mesma questão nos seguintes termos: "Finalmente, o que associa de maneira mais íntima trabalhadores da cidade e do campo é a circunstância de que a solução dos problemas essenciais de todos e o atendimento de suas reivindicações se confundem afinal num mesmo processo, que se pode comparar à tendência ao nivelamento dos líquidos em vasos comunicantes. Se as melhores condições de trabalho e emprego nos centros urbanos constituem, pela 
se explicaria pelo fato de o salário real médio dos empregados não ter acompanhado o aumento da produtividade média do trabalho, puxada para cima pela modernização de parte importante do setor produtivo.

A capacidade de absorção daquela economia em expansão seria uma variável-chave para se compreender a dinâmica daquele momento, e Rodríguez diverge das análises que afirmam que a elevada e prolongada participação do subemprego na estrutura ocupacional derivaria da baixa absorção da força de trabalho que caracteriza as tecnologias mais avançadas. Para ele, o elemento mais importante para se entender a heterogeneidade estrutural e o subemprego era o elevado nível do subemprego no início do período analisado, sobretudo no campo, que teria alimentado impiedosamente a oferta de trabalho nos centros urbanos, entre 1950 e 1980, o que reforçaria sua tese de que a variável-chave dessa equação é a concentração de terras no Brasil. No mesmo período em que a economia consolidava a indústria de bens de capital e de bens duráveis, exibindo uma das maiores taxas de crescimento econômico do mundo, a expulsão de trabalhadores rurais, dos quais quase 8,5 milhões já eram subempregados, foi intensificada ${ }^{53}$.

A enorme capacidade de absorção das atividades modernas implica que tais atividades geram uma demanda adicional de mão de obra superior ao de sua própria oferta adicional (excesso de demanda). Por sua vez, a incapacidade de absorção da agricultura atrasada implica que ela origina incrementos de oferta maiores que sua própria demanda (excesso de oferta). Durante certo tempo, esses excedentes de oferta superam, em termos absolutos, os excedentes de demanda das atividades modernas. Essa diferença forçosamente aumentará o subemprego urbano. Isso significa que as atividades não agrícolas de baixa produtividade absorverão, durante um tempo, antes mencionado, todos os incrementos de oferta que elas geram e, ademais,

concorrência que determinam no mercado comum de mão de obra, a principal, senão única circunstância capaz de elevar o poder de barganha dos trabalhadores rurais, doutro lado os baixos padrões dominantes no campo constituem dos principais fatores de depressão dos salários e agravamento das condições de emprego do trabalhador urbano. A massa trabalhadora rural se apresenta no Brasil como uma reserva permanente de mão de obra pouco exigente, sempre disposta a afluir para a cidade e aí se oferecer em condições mais favoráveis para os empregadores. Concorre assim muito seriamente com o trabalhador urbano, e tende por isso a lhe neutralizar as exigências" (Prado Júnior, 1987, p. 173).

Rodríguez (1985, p. 69-74). 
uma parte dos excedentes de oferta originados na agricultura atrasada, e, por fim, as magnitudes absolutas e relativas do subemprego urbano que são acrescidos. (Rodríguez, 1985, p. 70)

Ao fim, cabe salientar que, antes de se apontar a capacidade de absorção da indústria como grande vilã, era o direcionamento político que o Estado dava à dinâmica econômica que determinava em última instância a evolução da estrutura ocupacional. A política agrícola teria sido decisiva para que as atividades do campo conseguissem reter ou repelir pessoas que, às vezes impossibilitadas de seguir até mesmo com a agricultura de subsistência, migraram para os centros urbanos em busca de uma ocupação. Portanto, a chave para fazer retroceder a heterogeneidade estrutural derivaria da existência de políticas públicas que regulassem o fluxo de trabalhadores rurais. A execução desse objetivo requereria a implementação de medidas de longo prazo que assegurassem um aproveitamento mais equilibrado dos recursos disponíveis, o que não implicava necessariamente uma reforma agrária. Sua preocupação parecia estar mais relacionada à implementação de uma política agrícola mais justa, que ajudasse a encaminhar os problemas de emprego e distribuição de renda que se verificaram no decorrer dos processos de industrialização e urbanização ${ }^{54}$. Afinal, a maneira pela qual a agricultura atrasada foi desagregada é que determinou o caráter e a intensidade dos conflitos socioeconômicos nos anos em que a heterogeneidade assumiu uma nova forma.

\section{Conclusão}

A estrutura construída durante o passado colonial marcou toda a formação dos países latino-americanos, que não conseguem se organizar internamente em direção a um modelo autônomo. A estrutura de dominação forjada nesse período não apenas impõe uma estabilidade social e política que impediu a construção de mecanismos de integração como também atou a economia a uma especialização dependente da demanda externa, o que em boa medida foi preservado mesmo após ter sido dado

54 O autor, contudo, não entra em maiores detalhes sobre a questão. 
início aos processos de industrialização. Nem mesmo quando se internalizou estruturas econômicas mais modernas, que inicialmente se imaginava serem capazes de substituir parte considerável ou mesmo a totalidade do setor arcaico, os países da região se livraram da dependência. Pelo contrário, o que se observou foi o seu aprofundamento, que se manifestava de uma maneira diferente da que se manifestara no passado - afinal, aquela era a primeira vez que países latino-americanos instalavam setores produtivos mais modernos. Todavia, nem as filiais das transnacionais nem as classes dominantes de cada país pareciam interessadas em integrar a economia e a sociedade, que seguiriam heterogêneas. $\mathrm{O}$ modelo de desenvolvimento econômico, na verdade, dependia dessas desigualdades, para que fossem preservadas a dependência externa e a estabilidade social e política. Ou seja, o que o modelo induzia de forma previsível era a manutenção da América Latina como uma região subdesenvolvida, o que beneficiava apenas as classes dominantes e as suas respectivas classes médias, que consumiam tanto os bens duráveis que haviam sido internalizados como os importados. Por outro lado, a maioria da população continuava em ocupações de baixa produtividade, fosse no campo ou nas cidades. Assim, o subemprego tanto permanecia como forma importante de absorção da mão de obra, como atuava diretamente na perpetuação de um mercado interno pequeno, se assumimos que as atividades de baixa produtividade é que determinam o perfil da estrutura salarial, entrave este já apontado por Lewis e Nurkse. Segundo esses autores, assim como Furtado, essa estrutura ocupacional impõe limites à geração de um excedente capaz de quebrar o círculo vicioso do subdesenvolvimento.

Ainda que a revisão acima faça referência a meados do século passado, as estruturas continuam as mesmas, só que sob uma pressão ainda maior. A conjuntura histórica que se inicia no final da década de 1970, na América Latina, encerrou as ilusões que se alimentara no período substitutivo. Não apenas não foram realizadas reformas, como a reforma agrária, a desconcentração do crédito, o desenvolvimento tecnológico, dentre outras que poderiam ao menos mitigar as fragilidade estruturais, como os aparentes avanços do período anterior passaram e ainda passam por um processo de regressão, que, do ponto de vista econômico, assume duas feições principais. De um lado, avançou a desindustrialização e, de outro, a especialização regressiva, que nada mais é que o fortalecimento econômico e político do agronegócio, nome pelo qual o latifúndio pas- 
sou a ser chamado. Do ponto de vista socioeconômico, o que ocorreu foi a perda de empregos que foram substituídos pela desocupação, pelo subemprego e por empregos que estão cada vez mais próximos do subemprego.Ao mesmo tempo, a partir de uma nova expansão da fronteira agrícola, que ainda hoje avança, parece possível uma reprodução do êxodo rural, só que em menor escala.

Em suma, assumindo-se o subdesenvolvimento como uma formação autônoma que não necessariamente levaria ao desenvolvimento, tal como afirmou Celso Furtado inúmeras vezes, o fundamental do subdesenvolvimento seriam as estruturas de poder, que comandariam o sentido de sua evolução histórica e o caráter da economia e da sociedade ${ }^{55}$. Parece que, enquanto persistir esse padrão, o subemprego continuará a representar uma parcela significativa do mercado de trabalho.

\section{Referências bibliográficas}

BELLUZZO, Luiz Gonzaga de Mello. Distribuição de renda. Uma visão da controvérsia. In:TOLIPAN, Ricardo;TINELLI, Arthur Carlos. A controvérsia sobre a distribuição de renda e desenvolvimento. 2. ed. Rio de Janeiro: Zahar, 1978, p. 15-35.

CARDOSO, Fernando Henrique. Comentários sobre los conceptos de sobrepoblación relativa y marginalidad. Revista Latinoamericana de Ciencias Sociales. Santiago, n. 1-2, p. $57-76,1971$.

FERNANDES, Florestan. A revolução burguesa no Brasil. Ensaio de interpretação sociológica. 5. ed. Prefácio de José de Souza Martins. São Paulo: Globo, 2005.

FERNANDES, Florestan. A integração do negro na sociedade de classes. 5. ed. Prefácio de Antonio Sérgio Alfredo Guimarães. São Paulo: Globo, 2008a, 2 v.

FERNANDES, Florestan. Sociedade de classes e subdesenvolvimento. 5. ed. rev. Apresentação de Paul Singer. São Paulo: Global, 2008b.

FURTADO, Celso Monteiro. Desenvolvimento e subdesenvolvimento. Rio de Janeiro: Fundo de Cultura, 1961.

FURTADO, Celso Monteiro. A pré-revolução brasileira. 2. ed. Rio de Janeiro: Fundo de Cultura, 1962.

FURTADO, Celso Monteiro. Análise do "modelo" brasileiro. 2. ed. Rio de Janeiro: Civilização Brasileira, 1972.

FURTADO, Celso Monteiro. Prefácio a nova economia política. Rio de Janeiro: Paz e Terra, 1976.

55 Furtado (1976). 
FURTADO, Celso Monteiro. A nova dependência. Dívida externa e monetarismo. 5. ed. Rio de Janeiro: Paz e Terra: 1983.

FURTADO, Celso Monteiro. Formação econômica do Brasil.34. ed. Prefácio de Luiz Gonzaga de Mello Belluzzo. São Paulo: Companhia das Letras, 2006.

HOBSBAWM, Eric John Ernest. La marginalidad social en la historia de la industrialización europea. Revista Latinoamericana de Sociología. Buenos Aires, v.V,n. 1, p. 237-248, 1969.

KOWARICK, Lúcio. Capitalismo e marginalidade na América Latina. 2. ed. Rio de Janeiro: Paz e Terra, 1977.

LEWIS, William Arthur. O desenvolvimento econômico com oferta ilimitada de mão de obra.In:AGARWALA,A. N.;SINGH, S.P. (org.). A economia do subdesenvolvimento. Trad. Maria Celina Whately. Rio de Janeiro: Forense, 1969, p. 406-456.

MARX, Karl. O capital. Livro I: Crítica da economia política.Trad. Rubens Enderle. São Paulo: Boitempo, 2013.

NUN, José. Superpoblación relativa, ejército industrial de reserva y masa marginal. Revista Latinoamericana de Sociología. Buenos Aires, v.V, n. 1, p. 178-236, 1969.

NURKSE, Ragnar. Problemas da formação de capital em países subdesenvolvidos. Trad. Cid Silveira. Rio de Janeiro: Civilização Brasileira, 1957.

OLIVEIRA, Francisco Maria Cavalcanti de. Crítica à razão dualista. O ornitorrinco. São Paulo: Boitempo, 2003.

OLIVEIRA, Francisco de; MAZZUCCHELLI, Frederico. Padrões de acumulação, oligopólios e Estado no Brasil: 1950-1976. In: MARTINS, Carlos Estevam. Estado e capitalismo no Brasil. São Paulo: HUCITEC/CEBRAP, 1977, p. 111-139.

PINTO, Aníbal. Heterogeneidade estrutural e modelo de desenvolvimento recente. In: SERRA, José (coord.). América Latina. Ensaios de interpretação econômica. Rio de Janeiro: Paz e Terra, 1976, p. 44-82.

PORTUGAL JR., José Geraldo. Padrões de heterogeneidade estrutural no Brasil. Campinas: UNICAMP, 2012 (Tese de Doutorado em Economia da UNICAMP).

POSSAS, Mario Luiz.Valor, preço e concorrência: não é preciso recomeçar tudo desde o início. Revista de Economia Política. São Paulo, v. 2, n. 4, p. 71-110, 1982.

PRADO JÚNIOR, Caio. A revolução brasileira. 7. ed. São Paulo: Brasiliense, 1987.

PRADO JÚNIOR, Caio. Formação do Brasil contemporâneo. Colônia. Posfácio de Bernardo Ricupero. São Paulo: Companhia das Letras, 2011.

PRADO JÚNIOR, Caio. História econômica do Brasil. 43. ed. São Paulo: Brasiliense, 2012.

PREBISCH, Raúl. O desenvolvimento econômico da América Latina e alguns de seus problemas principais. In: BIELSCHOWSKY, Ricardo (org.). Cinquenta anos de pensamento na CEPAL.V. 1. Rio de Janeiro: Record, 2000.

QUIJANO, Anibal. The marginal pole of the economy and the marginalised labour force. Economy and Society. London: Routledge, v. 3, n. 4, p. 393-428, 1974.

QUIJANO,Anibal. Notas sobre o conceito de marginalidade. In: PEREIRA, Luiz (org.). Populações "marginais”. São Paulo: Duas Cidades, 1978, p. 11-71.

RODRÍGUEZ, Octavio. Agricultura, subempleo y distribución del ingreso. Notas del 
caso brasileño. Economía de América Latina. Ciudad de México: CIDE, n. 13, p. 63-77, 1985.

SOUZA, Paulo Renato Costa. Salário e emprego em economias atrasadas. Campinas: UNICAMP-IE, 1999.

SZMRECSÁNYI,Tamás.Análise das políticas para o setor agropecuário. In:BELLUZZO, Luiz Gonzaga de Mello; COUTINHO, Renata (orgs.). Desenvolvimento capitalista no Brasil. Ensaios sobre a crise.V. 2. 4. ed. Campinas: UNICAMP-IE, 1998.

TAVARES, Maria da Conceição. Problemas de industrialización avanzada en capitalismos tardíos y periféricos. Economía de América Latina. Ciudad de México: CIDE, n. 6, p. 21-42, 1981.

TAVARES, Maria da Conceição; SERRA, José. Más allá del estancamiento. Una discusión sobre el estilo de desarrollo reciente. El Trimestre Económico. Ciudad de México, v. 38, n. 152, p. 905-950, 1971. 